\title{
MAXIMUM PRINCIPLE FOR A FOURTH ORDER BOUNDARY VALUE PROBLEM
}

\author{
BO YANG
}

Abstract. We consider a boundary value problem for the beam equation. Some upper and lower bounds for positive solutions of the boundary value problem are obtained. As an application, some new sufficient conditions for the existence and nonexistence of positive solutions for the boundary value problem are established.

Mathematics subject classification (2010): 34B18, 34B15.

Keywords and phrases: Upper and lower bounds for the Green function, maximum principle, beam equation, positive solution.

\section{REFERENCES}

[1] R. P. AgaRwal, On fourth-order boundary value problems arising in beam analysis, Differential Integral Equations 2 (1989), 91-110.

[2] Z. BAI AND H. WANG, On positive solutions of some nonlinear fourth-order beam equations, J. Math. Anal. Appl. 270, 2 (2002), 357-368.

[3] R. Dalmasso, Uniqueness of positive solutions for some nonlinear fourth-order equations, J. Math. Anal. Appl. 201, 1 (1996), 152-168.

[4] J. DAVIS AND J. Henderson, Uniqueness implies existence for fourth-order Lidstone boundary value problems, Panamer. Math. J. 8, 4 (1998), 23-35.

[5] D. R. DUNNINGER, Multiplicity of positive solutions for a nonlinear fourth order equation, Ann. Polon. Math. 77, 2 (2001), 161-168.

[6] M. B. M. ElGindi AND Z. GUAN, On the global solvability of a class of fourth-order nonlinear boundary value problems, Internat. J. Math. Math. Sci. 20, 2 (1997), 257-262.

[7] J. R. GRAEF, J. HENDERSON, AND B. YANG, Positive solutions to a fourth order three point boundary value problem, Discrete and Continuous Dynamical Systems, Supplement 2009 (2009), 269-275.

[8] J. R. Graef, L. Kong, Q. Kong, And B. YAng, Positive solutions to a fourth order boundary value problem, Results. Math. 59 (2011), 141-155.

[9] J. R. GRAEF, L. KONG, AND B. YANG, Existence, nonexistence, and uniqueness of positive solutions to a three point fourth order boundary value problem, Nonlinear Studies 18, 4 (2011), 565-575.

[10] J. R. GRAEF AND B. YANG, Existence and nonexistence of positive solutions of fourth order nonlinear boundary value problems, Appl. Anal. 74 (2000), 201-214.

[11] J. R. GRAef And B. YAng, Positive solutions to a three point fourth order focal boundary value problem, Rocky Mountain J. Math. 44, 3 (2014), 937-951.

[12] C. P. GUPTA, A nonlinear boundary value problem associated with the static equilibrium of an elastic beam supported by sliding clamps, Internat. J. Math. Math. Sci. 12, 4 (1989), 697-711.

[13] M. A. Krasnosel's KiI, Positive Solutions of Operator Equations, Noordhoff, Groningen, 1964.

[14] N. Kosmatov, Countably many solutions of a fourth order boundary value problem, Electronic J. of Qualitative Theory of Differential Equations 2004, 12 (2004), 1-15.

[15] R. LIU AND R. MA, Existence of positive solutions for an elastic beam equation with nonlinear boundary conditions, Journal of Applied Mathematics 2014, Article ID 972135 (2014), 5 pages.

[16] R. MA, Existence and uniqueness theorems for some fourth-order nonlinear boundary value problems, Int. J. Math. Math. Sci. 23, 11 (2000), 783-788. 
[17] R. MA AND T. CHEN, Existence of positive solutions of fourth-order problems with integral boundary conditions, Boundary Value Problems 2011, Article ID 297578 (2011), 17 pages.

[18] T. F. MA, Positive solutions for a beam equation on a nonlinear elastic foundation, Math. Comput. Modelling 39, 11-12 (2004), 1195-1201.

[19] W. SHEN, Positive solutions for fourth-order second-point nonhomogeneous singular boundary value problems, Adv. Fixed Point Theory 5, 1 (2015), 88-100.

[20] J. R. L. Webb, G. Infante, And D. Franco, Positive solutions of nonlinear fourth-order boundary-value problems with local and nonlocal boundary conditions, Proceedings of the Royal Society of Edinburgh, 138A, (2008), 427-446.

[21] B. YANG, Positive solutions for a fourth order boundary value problem, Electronic J. of Qualitative Theory of Differential Equations 2005, 3 (2005), 1-17.

[22] B. YANG, Positive solutions for the beam equation under certain boundary conditions, Electronic Journal of Differential Equations 2005, 78 (2005), 1-8.

[23] Q. YAO, Positive solutions and eigenvalue intervals of a nonlinear singular fourth-order boundary value problem, Applications of Mathematics 58, 1 (2013), 93-110. 